\title{
Research on Network Lending Risk Analysis Based on Platform Efficiency
}

\author{
Dongmei $\mathrm{Li}^{1}$, Jin $\mathrm{Xu}^{2}$, Liping $\mathrm{Li}^{*}$ \\ ${ }^{1}$ School of Management, Shanghai University, Shanghai, China \\ ${ }^{2}$ School of Economics and Trade, Xingtai University, Xingtai, China \\ Email: *cecilia248185060@163.com
}

How to cite this paper: Li, D. M., Xu, J., \& Li, L. P. (2021). Research on Network Lending Risk Analysis Based on Platform Efficiency. Journal of Financial Risk Management, 10, 453-472.

https://doi.org/10.4236/jfrm.2021.104024

Received: October 27, 2021

Accepted: November 29, 2021

Published: December 2, 2021

Copyright (c) 2021 by author(s) and Scientific Research Publishing Inc. This work is licensed under the Creative Commons Attribution International License (CC BY 4.0).

http://creativecommons.org/licenses/by/4.0/

(c) (i) Open Access

\begin{abstract}
Optimizing the financial risk control mechanism is very important for small and medium-sized enterprises. It is an important foundation for lending companies to continue to operate steadily and ensure the safety of credit assets. Only by optimizing the financial risk control mechanism can small and medium-sized enterprises develop better and healthily. This study designs the data envelopment analysis (DEA) model (CCR and BCC) to evaluate the relative credit risk of the enterprise. According to the selected core indicators, comprehensive technical efficiency, pure technical efficiency and scale efficiency of each lending platform are calculated. In order to further explore the efficiency status of each lending platform and the reasons for its inefficiency, the efficiency pedigree was drawn according to the pure technical efficiency value and scale efficiency value of the platform. The main reason for the low efficiency of online loan platform was the low management level. Therefore, we need to improve the comprehensive management level of the platform, and strengthen the risk management control to improve the operation efficiency of the online loan platform. Finally the related policy proposal was put forward.
\end{abstract}

\section{Keywords}

Inclusive Finance, DEA, Efficiency, Risk Analysis

\section{Introduction}

Peer to Peer (P2P) network lending, personal to personal loan, is a business model that gathers a very small amount of funds to lend to people with capital needs. With the rapid development of the Internet, P2P network lending has been applied in various fields (Wang et al., 2020a). As an innovative financial lending product, $\mathrm{P} 2 \mathrm{P}$ online lending is implemented on the Internet platform. 
With the help of P2P technology and ecommerce technology, it lends idle funds owned by fund suppliers to fund demanders on the Internet platform, which breaks away from the traditional financial media. The Internet technology is used to match the fund supplier with the fund demander, which is different from the traditional loan mode of financial institutions.

The rapidly developing P2P network loan industry has solved the problem of insufficient financing needs and personal financial needs of small and medium-sized enterprises in China. From 2017 to 2019, the number of P2P online lending platforms has increased from 6584 to 6656, as shown in Figure 1. We can see that the number of platforms in P2P online lending industry has almost stopped growing. In 2017, there were 422 new platforms while only 71 new platforms were added in 2018 and only one new platform was added in 2019. It can be found that the number of new entrants in the P2P online lending industry has decreased significantly and even there has been no new platform for several consecutive months, which is in sharp contrast to the popularity in 2017.

In 2018, "Filing" has become the main keynote of the development of P2P online lending industry. In December 2017, the P2P platform was required to register and rectify. The qualified P2P platform is allowed to be filed and registered to ensure its normal operation. In the case of regulatory requirements for $\mathrm{P} 2 \mathrm{P}$ online lending platform to reduce the business scale, the number of lenders and borrowers, the scale of $\mathrm{P} 2 \mathrm{P}$ online lending industry is shrinking, and the number of exiting platform is increasing. The number of functioning platforms dropped sharply from 2448 in 2017 to 344 in 2019, in which not only a large number of platforms went out of business for transformation, but also a large number of problem platforms appeared, as shown in Figure 2. Among these problem platforms, according to the "zero one data" (https://www.01caijing.com), the number of websites closing platforms is the most, followed by the announcement of liquidation. In addition, the number of problem platforms with difficulty in cash withdrawal, closure of business, filing of cases, loss of contact and running away is also relatively high.

There are three main reasons for the significant decrease in the number of platforms. Firstly, the delay of filing has caused great uncertainty to the whole industry and many platforms choose to take the initiative to liquidate, transform or be dissuaded because they know that there is no hope of filing. Secondly, the

\section{CUMULATIVE NUMBER OF PLATFORMS}

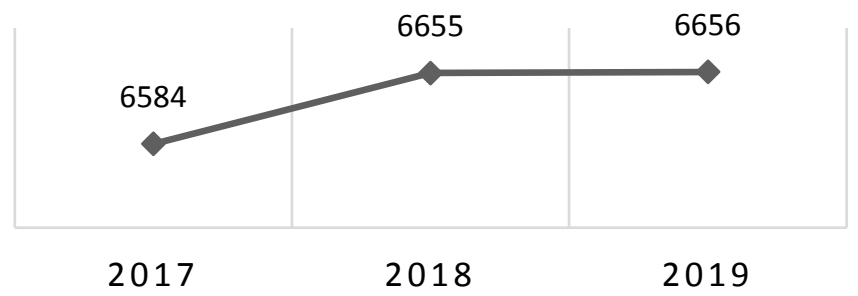

Figure 1. Cumulative number of platforms in China. Data source: https://www.wdzj.com. 


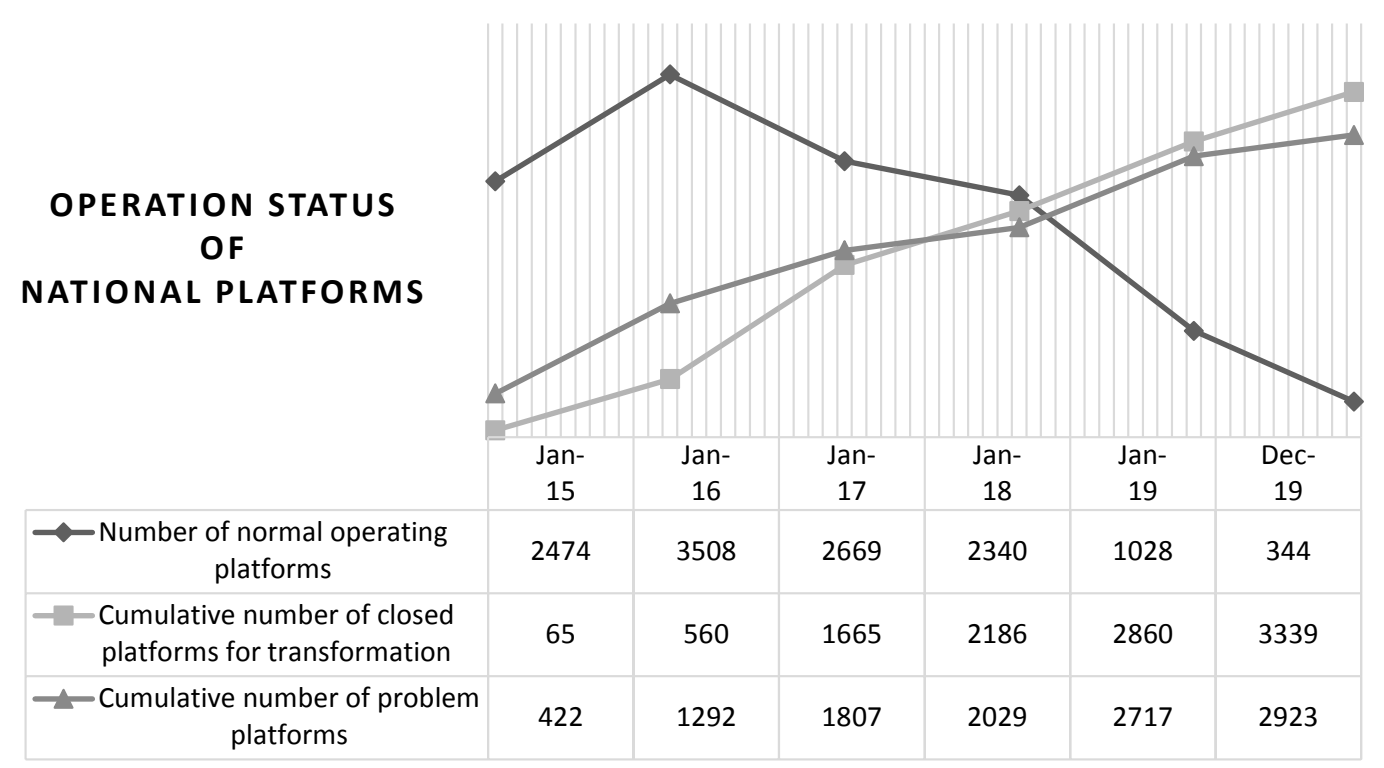

Figure 2. Operation status of national platforms. Data source: https://www.01caijing.com and https://www.wdzj.com.

supervision has become stricter, such as the notice on carrying out compliance inspection of $\mathrm{P} 2 \mathrm{P}$ online lending institutions issued by the online lending rectification office in August 2018. Finally, with the continuous emergence of problem platforms such as poor management, self-financing, and capital pool, investors lose confidence in the industry and the industry runs and the capital flow becomes tight, which makes a large number of platforms unable to adhere to operation due to lack of comprehensive strengthen (Gao et al., 2021; Gao et al., 2018).

Through the above analysis, we can see that under the new regulatory policies and domestic situation in China, many $\mathrm{P} 2 \mathrm{P}$ companies have withdrawn from the market, and some companies are also facing transformation. Importantly, most platforms lack experience in risk management. They have no risk dynamic assessment system and risk quantitative indicators. This leads to the risk management method being too fragmented, simplified and unsystematic. Therefore, it is very important for the healthy development of lending platforms, especially small and medium-sized enterprises, to optimize the financial risk control mechanism.

Herein, in this paper, we first analyze the current situation and development trend of P2P platforms in China. Then, the methods of risk control analysis reported in the literature are reviewed. Besides, the models and methods used in this study are proposed. Subsequently, we analyzed the selected quantitative indicators and evaluated the risks in the lending business. Finally, we discussed the results and put forward suggestions for improving risk control management.

\section{Literature Review}

As technologies of big data and blockchain advancing, the financial credit risk 
and risk profile in the context of the Internet has become a popular research subject (Zhao et al., 2021; Song et al., 2018; Liu, 2020; Ahelegbey et al., 2019). P2P online lending originated in foreign countries. The earliest P2P online lending platform in the world is Zopa in the UK, which was established in London in March 2005. The new financial industry represented by peer-to-peer lending has gradually become a new source of risk due to the increasing complexity of the Chinese financial market (Fang et al., 2018). In 2007, China established its first P2P network lending enterprise (Paipai dai company). P2P lending platforms have different backgrounds and the transparency of information. Moreover, P2P is divided into bank series, state owned, venture capital series, listing series, etc. according to different background categories (Zhang et al., 2020). It is worth noting that platform background is related to operational risk (Wang et al., 2020b; Ma et al., 2020).

The most important step of credit risk management is to evaluate credit risk effectively. Only combining with the situation of P2P network lending industry, we can choose a reasonable credit risk assessment model. Then, we can establish a complete credit risk assessment system to effectively manage the credit risk of P2P network lending platform. The evaluation model of credit risk includes not only traditional evaluation management model, but also modern evaluation management model and some new methods. The following will introduce these models and choose the model suitable for China's P2P Internet financial industry credit risk assessment and management.

\subsection{Common Models of Credit Risk Measurement}

There are many ways to measure credit risk, including expert analysis, Fisher linear discriminant analysis, Z-score model and so on.

For protecting the obtaining its interests and obtaining the confidence, banks must carefully evaluate the nature, capabilities, capital, collateral, and business prospects of their debts or their customers, called "5C" (Wahyuni, 2017). The " $5 C$ " analysis method is commonly used in expert analysis, which quantifies the relevant factors that affect the business performance, such as character, capital, capacity, condition and collateral, and then obtains the credit rating of the enterprise by weighted average. This method needs to rely on the professional opinions of experts. When experts evaluate enterprises, they mainly consider the above five elements. The most common problem in financial service industry is risk. One of the most critical risks is the default risk. One evaluation model used by Franata, Faturohman and Rahadi is 5C credit analysis (Franata et al., 2018). According to the analysis of data by $5 \mathrm{C}$ analysis tools, researchers found that most borrowers could obtain a credit from PD. In general, the credit approval process includes credit application, research documents, bank information search, site visits, credit research analysis (Mardhotillah, 2019). The expert method is relatively comprehensive, but it is not difficult to see that this method will bring some subjectivity, too many qualitative components, and the opinions 
of each expert will be different, which makes the quantitative results have some errors.

The main idea of Fisher linear discriminant method is to construct a discriminant function, which is constructed from the observed values of known classification samples, and the constructed indexes are not related to each other. Then we can calculate the mean value of each classified comprehensive index, that is, the center point, and then bring the single sample to be verified into the discriminant function to calculate the distance to each center point. According to the results, we can classify the new sample into the nearest one. An application on credit scoring data is provided, Credit scoring can be considered as a technology to provide a basis for whether a credit provider grants credit to a customer. Moreover, a linear mixed model (LMM) was proposed as a new method to evaluate the credit risk of financial companies (Casin, 2018; Pérez-Martín et al., 2018). The premise of Fisher linear discriminant method is that the independent variables need to obey normal distribution, and the total covariance matrix of each group should be equal, which is not true in practical problems.

Altman (1968) put forward the Z-score Model. The model screened out five representative financial indicators of the same number of normal operating companies and defaulted companies through selection analysis. It established a multivariate linear model to get a total discriminant value, which is defined as $\mathrm{Z}$-value. The conclusion is that when $\mathrm{Z}$ value is less than 1.81 , the borrower is expected to default, indicating the great risk. When $\mathrm{Z}$ value is greater than 2.99 , the risk of default is small. When $\mathrm{Z}$ value is between 1.81 and 2.99 , the financial situation of the enterprise is unstable, so we need to continue to pay attention to the operation of the enterprise (Panigrahi, 2019). Although the Altman Z-score is "outdate", it is still the standard to measure most other bankruptcy or default prediction models. Furthermore, in numerous empirical studies, it is also regarded as the benchmark of credit risk measurement by researchers (Altman, 1968; Altman, 2018a; Altman, 2018b). Kabir et al. used Morton's distance to default model and Z-score model to assess the credit risk of 156 traditional banks and 37 Islamic banks in 13 countries from 2000 to 2012. The results show that the Islamic banks' credit risk was obviously lower than that of traditional banks based on Morton's default distance model (Kabir et al., 2015). However, according to the Z-score Model, Islamic banks shows higher credit risk and non-performing loan ratio. The results indicated that which model to choose to evaluate the credit risk of Islamic banks has a very different impact on the results. Tung and Phung have evaluated the bankruptcy risk of a series of different types of multidisciplinary companies by Altman Z-score model including small and medium-sized enterprise. Data comes from the official financial reports of 180 companies (Tung and Phung, 2019). Siekelova, Kovalova and Ciurlău predicted the financial health of the company by Altman's Z score in 2019 (Siekelova et al., 2019). The empirical results showed that the improved Z-score model has $98.6 \%$ accuracy in predicting bank credit risk while the original Z-score Model Using 
Altman has only $93.5 \%$ accuracy. At the same time, the new converted financial ratio can predict $93.2 \%$ bankruptcy probability while the original Z-score Model Using Altman has only 87.4\% effectiveness. Therefore, the advantage of $\mathrm{Z}$-score Model is to assess the credit status of companies according to the financial data of enterprises. The data is easy to obtain and has strong operability. However, in this multivariate linear model, the weight of each index and the benchmark setting of $\mathrm{Z}$ value need to be adjusted according to the actual situation, which leads to the enhancement of subjectivity and the lack of a unified standard.

\subsection{Credit Risk Model Based on Specific Theory}

As time goes on, more and more scholars used different tools and measurement methods to study credit risk and many advanced credit risk measurement models emerged (Yeh et al., 2012; Hamerle and Rösch, 2006; Tian, 2018). Among them, KMV model based on option pricing theory, CPV model based on macro simulation, CreditMetrics model based on VaR and CreditRisk+ model based on actuarial theory were the most widely used.

KMV model was developed from the theory of option pricing (Crouhy et al., 2000). Since all the information of listed companies is reflected in the stock price, KMV company first proposed to apply the option pricing model to the capital market to evaluate the credit risk of enterprises in 1997. Zeng and Jiang analyzed the credit risk of four listed insurance companies in China by the improved KMV model. They found that the default distance of Chinese listed insurance enterprises has reduced in different level during the outbreak of the epidemic, demonstrating that the epidemic has temporarily increased the credit risk of the industry (Zeng et al., 2021).

The basic idea of CPV model is that macroeconomic factors are important factors which affect the change of credit rating (Cheng and Zou, 2009). The credit quality of financial institutions depends on economic development (Michalkova and Michalikova, 2017). Because the loan portfolio can only reduce the non-systematic risk, the loan portfolio can't be reduced for the systematic risk caused by macroeconomic factors. CPV model can simulate the economic state to take multiple macroeconomic variables as the explanatory factors of the model and transform the conversion function into default probability to explain the default caused by macroeconomic changes (Bülbül et al., 2019). The advantage of PV model is to use a mark to market method, which not only applies to a single sample, but also can describe the risk of a group of samples and give the specific loss distribution. However, CPV model requires to obtain the default data of each country or industry in advance, so it is not easy to gain the data.

CreditMetrics model was proposed by JP Morgan in 1997 (Morgan, 1997). The model is based on the theory of value at risk (VaR). According to the historical default rate of the borrower and the credit rating transfer matrix given by the rating company, the distribution curve is obtained and the VaR value is cal- 
culated to assess the credit risk of the loan enterprise. However, the model can't reflect the change of enterprise credit status in time because of the defect of the model which the enterprise credit rating will not change easily (Tian, 2018). The following key indicators need to be calculated to assess the CR of PPP projects, including the default probability (DP), the recovery rate (RR) and the exposure at default (EAD). The DP was analyzed by using improved Credit Metrics model and Monte Carlo simulation. Moreover, the evaluation method was successfully applied in the case of PPP financial project (Wang et al., 2020c).

CreditRisk+ model is based on actuarial theory to study the default risk of loan. Debali explains the different characteristics of CreditRisk+ model, and thinks that it can calculate the default probability of credit portfolio (Derbali, 2018). In the credit risk model, the numerical calculation of the risk measure is equivalent to evaluating the tail expectation of the investment loss distribution. Although the moment generating function of the loss distribution was obtained with analytical closed form in CreditRisk + model, it is still a challenge to calculate risk measurement and risk contribution efficiently, accurately and reliably (Kwok, 2020). For the loan portfolio, the model first classifies the loans with similar default loss rate into a group and assumes that the default probability follows Poisson distribution to calculate the default loss distribution of this group of loans. The other groups with similar default loss rate are also based on this algorithm. By summing up the data of each group, we can get the loss distribution of the loan portfolio and then calculate the risk of the portfolio (Sanfins et al., 2020).

\subsection{Credit Risk Model Based on Machine Learning}

As the development of science and technology and the more and more extensive application of computer, the method of learning from data has also been introduced to the field of credit risk measurement, among which back propagation (BP) neural network and support vector machine (SVM) are more active.

As many machine learning and data mining technologies are applied to financial decision-making, the research on credit risk assessment has attracted a lot of attention. BP neural network has become a common choice for credit risk assessment, but many researchers point out that classifier integration is better than a single classifier (Shen et al., 2019). BP neural network is mainly composed of two processes of information forward propagation and back propagation. The neural network is composed of input layer, middle layer and output layer. Guo assessed the traditional financial risk and information technology risk of P2P lending companies by analyzing the large-scale lending data from 2015 to 2019. They found that the algorithm based on BP neural network can effectively decrease the risk of investors (Guo, 2020). In Zhou's study, they have proposed a big data mining method based on particle swarm optimization (PSO) back propagation (BP) neural network. This method is used for financial risk management of commercial banks deploying the Internet of things. On the data sets 
of on or off balance sheet items, a nonlinear parallel optimization model was constructed by using Apache spark and Hadoop HDFS technology (Zhou et al., 2019). The research results of $\mathrm{Du}$, $\mathrm{Liu}$ and $\mathrm{Lu}$ showed that BP neural network has good accuracy and calculation efficiency in early warning and evaluation of network credit risk. This not only makes BP neural network applied in the field of Internet finance, but also opens a new window for Internet credit risk early warning and evaluation (Du et al., 2021). The advantage of this method is that the basic idea is simple and easy to understand and it can deal with the problem of data classification and complex relationship. However, BP neural network in the setting of learning mechanism is complex and time-consuming, and requires sufficient training samples and professional computer and mathematical basis, which increases the difficulty of dealing with the problem.

Corinna and Vapnik proposed support vector machine (SVM) method (Cortes and Vapnik, 1995). With the development of time, this method was widely used in nonlinear separable classification problems. The basic idea of SVM is to minimize the structural risk and separate the two kinds of sample data accurately. The biggest advantage of support vector machine is that it can solve the nonlinear and small sample problem. Considering that the parameters we choose have a great impact on the performance of SVM, so it is our previous work to optimize it (Wang and Li, 2019).

\subsection{Research on the Theory and Method of Efficiency Evaluation}

Financial inclusion is based on the requirements of equal opportunities and the principle of business sustainability to provide appropriate and effective financial services for all social strata and groups with financial service needs at an affordable cost. It is crucial to a country's competitiveness (Wang et al., 2021). After analyzing the advantages and disadvantages of different models, we can find that there is no unified scheme for credit risk measurement. The purpose is to propose the research scheme of credit risk measurement of P2P network lending platform and introduce the models and main methods involved in the empirical study.

A. Charnes and W. W. Cooper have put forward the data envelopment analysis, which is an input-output ratio to study the effectiveness of decision-making units. The advantage of data envelopment analysis is that subjective factors can be eliminated because there is no need to know the form of production function. Moreover, it has less research constraints and is useful for the efficiency assessment of multiple inputs and outputs (Charnes et al., 1997). DEA model began to be applied in the field of business efficiency evaluation and financial health evaluation (Mendelová and Tatiana, 2017). Wei Chen et al. study the problem about evaluating fuzzy portfolio efficiency under different risk measures. DEA model shows some advantages in diagnosing bankruptcy (Chen et al., 2018). DEA has some novelty as a nonparametric method compared with the traditional statistical methods. It can not only be applied to determine the bankruptcy 
risk, but also evaluate a single production unit according to the whole sample (Horváthová and Mokrišová, 2018).

Davis et al. believe that P2P online lending has injected fresh vitality into the traditional lending market to meet the needs of investors and consumers. The platform's operation and management capacity, organizational production capacity and environment are very important. The imbalance of these factors will lead to the platform's resources and opportunities ineffective, resulting in the collapse of the platform (Razi et al., 2004). The survival of the platform depends on the age, scale and life cycle of the enterprise (Bruton and Rubanik, 2002). The management ability of platform operators plays a key role in the success or failure of small and micro platforms (Honjo, 2000). There is a relationship between the scale of the platform and its failure, which the smaller the scale of the platform, the greater the possibility of its failure (Kale and Arditi, 1998; Stokes and Blackburn, 2002). Therefore, data envelopment analysis is widely used. Based on the above research literature, this study considered the availability of platform operational data and operational risk factors. In this study, DEA-CCR and DEA-BCC model were used to analyse the data of the sample platform.

China's internet finance is developing rapidly and on a large scale, which has great influence on China's economy. The central bank has successively formulated the regulatory system on the Internet lending platform, marking that the Internet financial lending platform is basically under systematic supervision. Therefore, this study chose the Internet financial lending platform as the research object to conduct risk control evaluation research. According to the selected core indicators, the comprehensive efficiency, pure technical efficiency and scale efficiency of each lending platform are calculated by using the classic DEA model (CCR and BCC). According to the comprehensive efficiency performance, it can include three grades: excellent, good and medium. Moreover, different from the traditional machine learning methods, this study analyzes and optimizes the DEA model from the perspective of multi input and multi output.

Online lending banks are developing rapidly, and many platforms have defaulted when new platforms are established. On the one hand, the rapidly increasing online lending platform provides investors with more convenient and diversified services. On the other hand, it makes choice more difficult. Compliant online loan platforms generally operate in a standardized manner. The possibility of default is relatively small, and its risk control audit is also relatively strict. Compliant online loan platforms generally operate in a standardized manner. The possibility of default is relatively small, and its risk control audit is also relatively strict. The risk assessment of online loan platform needs to comprehensively consider many factors. This paper proposes to conduct risk analysis from the perspective of platform risk efficiency.

\section{Methods}

In 1978, the first classic DEA model, CCR model, was put forward by Charnes, 
Cooper and Rhode. This research uses the DEA-CCR model to evaluate the comprehensive technical efficiency of the P2P platform. CCR model assumes constant returns to scale, which is usually called comprehensive technical efficiency, because its technical efficiency includes the component of scale efficiency. Assuming that there are $N$ decision-making units $\operatorname{DMU}_{j}(j=1,2, \cdots, n)$, and each decision-making unit has $M$ inputs, denoted as $X_{i}(i=1,2, \cdots, m), Q$ outputs, denoted as $Y_{r}(r=1,2, \cdots, q)$. The DMU currently to be measured is denoted as $\mathrm{DMU}_{k} . \lambda$ represents the coefficient of the linear combination of DMU and the optimal solution of the model $\theta^{*}$ represents the efficiency value of DMU. The range of $\theta^{*}$ is $(0,1]$. The smaller the $\theta^{*}$, the larger the input can be reduced and the lower the efficiency. The CCR model formula can be expressed as follows:

$$
\begin{aligned}
& \min \theta \\
& \text { s.t. }\left\{\begin{array}{l}
\sum_{j=1}^{n} \lambda_{j} X_{i j} \leq \theta X_{i k} \\
\sum_{j=1}^{n} \lambda_{j} Y_{r j} \geq Y_{r k} \\
\lambda_{j} \geq 0 \\
i=1,2, \cdots, m \\
r=1,2, \cdots, q \\
j=1,2, \cdots, n
\end{array}\right.
\end{aligned}
$$

where, $X_{i}$ is the $i$-th input indicator of DMU and $X_{i j}$ is the $i$-th input indicator of $j$-th DMU. $Y_{r}$ is the $r$-th output index of DMU, and $Y_{r j}$ is the $r$-th output index of $j$-th DMU.

In 1984, Banker et al. gave a DEA model for evaluating variable returns to scale for certain problems that did not satisfy the convex cone hypothesis, which is generally abbreviated as the BCC model. Through this model, the technical effectiveness of the decision-making unit can be described. The BCC model is based on the CCR model by adding constraint conditions $\sum_{j=1}^{N} \lambda_{j}=1(\lambda \geq 0)$ to obtain a BCC model for solving pure technical efficiency. The formula is as follows:

$$
\begin{aligned}
& \min \theta \\
& \text { s.t. }\left\{\begin{array}{l}
\sum_{j=1}^{n} \lambda_{j} X_{i j} \leq \theta X_{i k} \\
\sum_{j=1}^{n} \lambda_{j} Y_{r j} \geq Y_{r k} \\
\sum_{j=1}^{n} \lambda_{j}=1 \\
\lambda_{j} \geq 0 \\
i=1,2, \cdots, m \\
r=1,2, \cdots, q \\
j=1,2, \cdots, n
\end{array}\right.
\end{aligned}
$$

The scale efficiency can be obtained by the following formula:

Comprehensive technical efficiency $=$ Pure technical efficiency $*$ Scale efficiency (3)

Using the selected methods in this study, the results will not be affected by 
different input-output units. Besides, the evaluation of DMU is fair without the influence of human subjective factors. Importantly, the analysis of multiple inputs and outputs, efficiency and variables can guide the direction of risk management for decision makers.

\section{Efficiency Analysis of P2P Platform}

Firstly, this chapter introduced the screening principles, data sources and processing methods of sample indicators. Secondly, it introduced the DEA method and the reasons and empirical results of using this method to evaluate the relative credit score of enterprises. Finally, a summary of this chapter was given.

\subsection{Calculation of the Efficiency Value}

The data source is the first quarter of 2019 data of Internet financial companies provided by the website data platform of "Wangdaizhijia" (https://www.wdzj.com). Data indicators include registered capital, expected rate of return, average loan period (months), transaction points, popularity points, technology points, leverage points, liquidity points, dispersion points, transparency points, brand points, compliance points and other indicators. The meaning of the indicators is shown in Table 1.

Six core indicators were selected from the Internet financial risk evaluation indicators and used as the input-output indicator system of the DEA model for further research. The indicators of the Internet financial risk model are shown in Table 2. According to the meaning of the indicators, the registered capital (ten thousand yuan) and technical points are selected as the input indicators of the model. The four indicators including liquidity points, leverage points, dispersion points, and transparency points represent are selected as the output variables of the model to characterize the operational risk of the platform from different dimensions.

The three major efficiency values including comprehensive technical efficiency (TE), pure technical efficiency (PTE), and scale efficiency (SE) and return to scale (RTS) of each P2P online lending company are obtained from the classic DEA model (CCR, BCC). The calculation results are shown in Table 3.

The comprehensive technical efficiency of 17 out of 39 platforms is equal to 1 , indicating that the performance level of these platforms is DEA effective. However, there are still many platforms with low performance level, and the development of pure technical efficiency, scale efficiency and comprehensive technical efficiency are not synchronous.

There are 27 platforms in the sample whose pure technical efficiency is equal to 1 . For some platforms where pure technical efficiency is not effective, attention should be paid to the rational allocation and effective use of input resources, and the maximum benefit of input factors should be brought into play by improving the structure of input factors.

The closer the scale efficiency is to 1 , the closer the project is to the most ap- 
propriate size. According to the measured sample data, the scale efficiency of 22 platforms is equal to 1 , indicating that these projects have been in a fixed scale

Table 1. Internet financial risk evaluation index system. Data source: https://www.wdzj.com.

\begin{tabular}{|c|c|c|}
\hline NO. & Indicators & Meaning \\
\hline 1 & $\begin{array}{l}\text { Registered Capital } \\
\text { (ten thousand) }\end{array}$ & $\begin{array}{l}\text { As the capital investment of the registered capital, the assets that can form the P2P platform are the } \\
\text { guarantee and basis for it to bear the operating risks and risk responsibilities. }\end{array}$ \\
\hline 2 & $\begin{array}{l}\text { Expected Rate of } \\
\text { Return (\%) }\end{array}$ & $\begin{array}{l}\text { It is used to characterize the variable cost of platform operation. Now that the online loan industry is } \\
\text { increasingly standardized and operating costs are gradually rising, online loan platforms with high } \\
\text { interest rates often have large investment traps, so investors get reasonable through P2P platforms. } \\
\text { To some extent, the expected return reflects the robustness of platform operations and the effective- } \\
\text { ness of risk management and control. }\end{array}$ \\
\hline 3 & Transaction Points & $\begin{array}{l}\text { An indicator used to characterize the trading volume of the platform. If the transaction score is high- } \\
\text { er, the transaction volume of the platform will be higher. }\end{array}$ \\
\hline 4 & Popularity Points & $\begin{array}{l}\text { An indicator used to characterize the number of investors and borrowers on the platform. The higher } \\
\text { the popularity score, the more people will invest and borrow on this platform. }\end{array}$ \\
\hline 5 & Liquidity Points & $\begin{array}{l}\text { In addition to the liquidity of investors, the liquidity of the platform will also be considered. Net out- } \\
\text { flow indicators and future repayment pressure indicators will be established. For platforms with a } \\
\text { shorter project period, the liquidity points will be lower. }\end{array}$ \\
\hline 6 & Leverage Points & $\begin{array}{l}\text { An indicator used to characterize the risk tolerance of the platform. If the leverage point is higher, the } \\
\text { potential capital leverage of the platform is smaller and the risk tolerance is higher. }\end{array}$ \\
\hline 7 & Dispersion Points & $\begin{array}{l}\text { An indicator used to characterize the diversification of platform borrowing and investment funds. If } \\
\text { the diversification score is higher, it indicates that the investment and borrowers of the platform are } \\
\text { more diversified, and the operating risk of the platform is lower. }\end{array}$ \\
\hline 8 & Technology Points & $\begin{array}{l}\text { An indicator used to characterize the technical strength of the platform. If the technical score is } \\
\text { higher, the stronger the technical strength of the platform is. }\end{array}$ \\
\hline 9 & Transparency Points & $\begin{array}{l}\text { An indicator used to characterize the transparency of platform information. The higher the transparency } \\
\text { score is, the more open the platform information is and the more transparent the platform is. }\end{array}$ \\
\hline 10 & Brand Points & $\begin{array}{l}\text { An indicator used to characterize the popularity of the platform. If the platform brand score is higher, } \\
\text { it means that its popularity is higher and it can be recognized by the lender. }\end{array}$ \\
\hline 11 & Compliance Points & $\begin{array}{l}\text { An indicator used to characterize the degree of compliance of the platform and the difficulty of } \\
\text { compliance transformation at this stage. According to regulatory opinions, each business require- } \\
\text { ment and prohibited items are quantified, and the degree of compliance of the platform is graded. }\end{array}$ \\
\hline
\end{tabular}

Table 2. Internet financial risk model indicators.

\begin{tabular}{ccc}
\hline Index nature & NO. & Index \\
\hline \multirow{2}{*}{ Investment index } & $X_{1}$ & Registered capital (ten thousand yuan) \\
& $X_{2}$ & Technology Points \\
\hline Output indicators & $X_{3}$ & Liquidity Points \\
& $X_{4}$ & Leverage Points \\
& $X_{5}$ & Dispersion Points \\
& $X_{6}$ & Transparency points \\
\hline
\end{tabular}


Table 3. The calculation results of the three efficiency values and scale returns of P2P online loan companies. The main source of data: calculated by DEAP Version 2.1.

\begin{tabular}{|c|c|c|c|c|c|c|}
\hline Ranking & Code & Platform & $\mathrm{TE}$ & PTE & SE & RTS \\
\hline 1 & 1 & DMU1 & 1.00 & 1.00 & 1.00 & Constant \\
\hline 2 & 4 & DMU4 & 1.00 & 1.00 & 1.00 & Constant \\
\hline 3 & 8 & DMU8 & 1.00 & 1.00 & 1.00 & Constant \\
\hline 4 & 12 & DMU12 & 1.00 & 1.00 & 1.00 & Constant \\
\hline 5 & 13 & DMU13 & 1.00 & 1.00 & 1.00 & Constant \\
\hline 6 & 14 & DMU14 & 1.00 & 1.00 & 1.00 & Constant \\
\hline 7 & 18 & DMU18 & 1.00 & 1.00 & 1.00 & Constant \\
\hline 8 & 20 & DMU20 & 1.00 & 1.00 & 1.00 & Constant \\
\hline 9 & 25 & DMU25 & 1.00 & 1.00 & 1.00 & Constant \\
\hline 10 & 26 & DMU26 & 1.00 & 1.00 & 1.00 & Constant \\
\hline 11 & 27 & DMU27 & 1.00 & 1.00 & 1.00 & Constant \\
\hline 12 & 30 & DMU30 & 1.00 & 1.00 & 1.00 & Constant \\
\hline 13 & 33 & DMU33 & 1.00 & 1.00 & 1.00 & Constant \\
\hline 14 & 34 & DMU34 & 1.00 & 1.00 & 1.00 & Constant \\
\hline 15 & 36 & DMU36 & 1.00 & 1.00 & 1.00 & Constant \\
\hline 16 & 38 & DMU38 & 1.00 & 1.00 & 1.00 & Constant \\
\hline 17 & 39 & DMU39 & 1.00 & 1.00 & 1.00 & Constant \\
\hline 18 & 24 & DMU24 & 0.99 & 1.00 & 0.99 & Increasing \\
\hline 19 & 35 & DMU35 & 0.98 & 0.99 & 0.99 & Decreasing \\
\hline 20 & 2 & DMU2 & 0.97 & 1.00 & 0.97 & Decreasing \\
\hline 21 & 17 & DMU17 & 0.97 & 1.00 & 0.97 & Decreasing \\
\hline 22 & 28 & DMU28 & 0.97 & 1.00 & 0.97 & Decreasing \\
\hline 23 & 6 & DMU6 & 0.97 & 1.00 & 0.97 & Decreasing \\
\hline 24 & 7 & DMU7 & 0.97 & 1.00 & 0.97 & Increasing \\
\hline 25 & 16 & DMU16 & 0.96 & 0.96 & 1.00 & Increasing \\
\hline 26 & 37 & DMU37 & 0.95 & 1.00 & 0.95 & Increasing \\
\hline 27 & 19 & DMU19 & 0.92 & 0.99 & 0.93 & Increasing \\
\hline 28 & 23 & DMU23 & 0.9 & 0.93 & 0.97 & Increasing \\
\hline 29 & 21 & DMU21 & 0.9 & 0.91 & 1.00 & Increasing \\
\hline 30 & 10 & DMU10 & 0.89 & 0.91 & 0.98 & Increasing \\
\hline 31 & 31 & DMU31 & 0.88 & 0.89 & 0.99 & Increasing \\
\hline 32 & 29 & DMU29 & 0.88 & 1.00 & 0.88 & Decreasing \\
\hline 33 & 5 & DMU5 & 0.87 & 0.87 & 1.00 & Constant \\
\hline 34 & 32 & DMU32 & 0.86 & 0.89 & 0.97 & Increasing \\
\hline 35 & 9 & DMU9 & 0.86 & 0.86 & 1.00 & Increasing \\
\hline 36 & 22 & DMU22 & 0.86 & 1.00 & 0.86 & Decreasing \\
\hline 37 & 11 & DMU11 & 0.85 & 1.00 & 0.85 & Decreasing \\
\hline 38 & 3 & DMU3 & 0.82 & 0.82 & 1.00 & Constant \\
\hline 39 & 15 & DMU15 & 0.75 & 0.79 & 0.95 & Increasing \\
\hline
\end{tabular}


return state. On the other hand, the increase and decrease of returns to scale can also reflect the direction of optimization and adjustment for platforms with economies of scale below 1. Platforms with increasing economies of scale need to increase factor input to get more output. For platforms with diminishing economies of scale, it is necessary to reduce the input of existing factors to improve platform performance.

\subsection{Result Analysis}

\subsubsection{Rating Classification}

According to the comprehensive efficiency value in Table 3, we distinguished the effective and ineffective comprehensive efficiency of P2P network lending platform. Besides, we classified and analyzed the level of platform efficiency, and then observed the efficiency distribution of the platform as a whole. These provide support for online loan platform risk management and risk assessment. The efficiency amplitude $A$ is equal to the maximum value of the efficiency minus the minimum value of the efficiency, that is, $A=0.24528$. The step size of classification is $d=A / n$.

According to this step size, each lending platform can be divided into 3 categories. Therefore, the 39 lending platforms involved in this paper are divided into three categories, including excellent, good, and medium. Therefore, the dividing lines for each category are 0.9182 and 0.8365 respectively. The rating classification distribution map shown in Figure 3. There are 27 sample P2P lending platforms with excellent comprehensive efficiency, accounting for $69.2 \%$. There are 10 sample P2P lending platforms with good comprehensive efficiency, accounting for $25.6 \%$. And there are two medium-level platforms, accounting for $5.1 \%$.

\subsubsection{Efficiency Pedigree Analysis}

In the DEA model, the comprehensive efficiency is equal to the multiplication of pure technical efficiency and scale efficiency. In order to further explore the efficiency status of each lending platform and the reasons for its inefficiency, an efficiency pedigree diagram is drawn based on the calculation results in Table 3. Efficiency spectrum of online lending platform is shown in Figure 4. The chart is divided into four areas by a dividing line, including high scale efficiency and low technical efficiency, high pure technical efficiency and high scale efficiency, low pure technical efficiency and low scale efficiency, low scale efficiency and high technical efficiency. Therefore, dual-high type platforms have better technical efficiency and scale efficiency. The technical efficiency of the "high scale and low-tech type" platform needs to be improved, and the scale efficiency of the "high-tech and low scale type" platform needs to be improved.

Among them, $11 \mathrm{P} 2 \mathrm{P}$ lending platforms are comprehensive and effective, that is, they are both technically effective and scale effective. The loan platform codes are $1,4,8,12,13,14,18,20,25,25,27,30,33,34,36,38$ and 39 respectively (the platform name can be queried through Table 3 , the same above). Comprehensive 


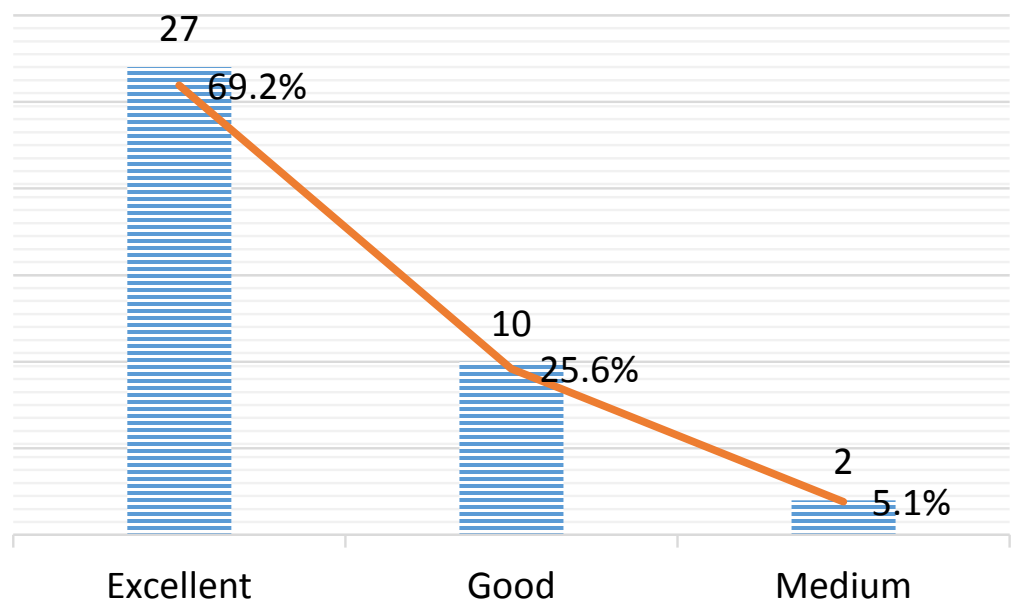

Figure 3. Rating classification distribution map.
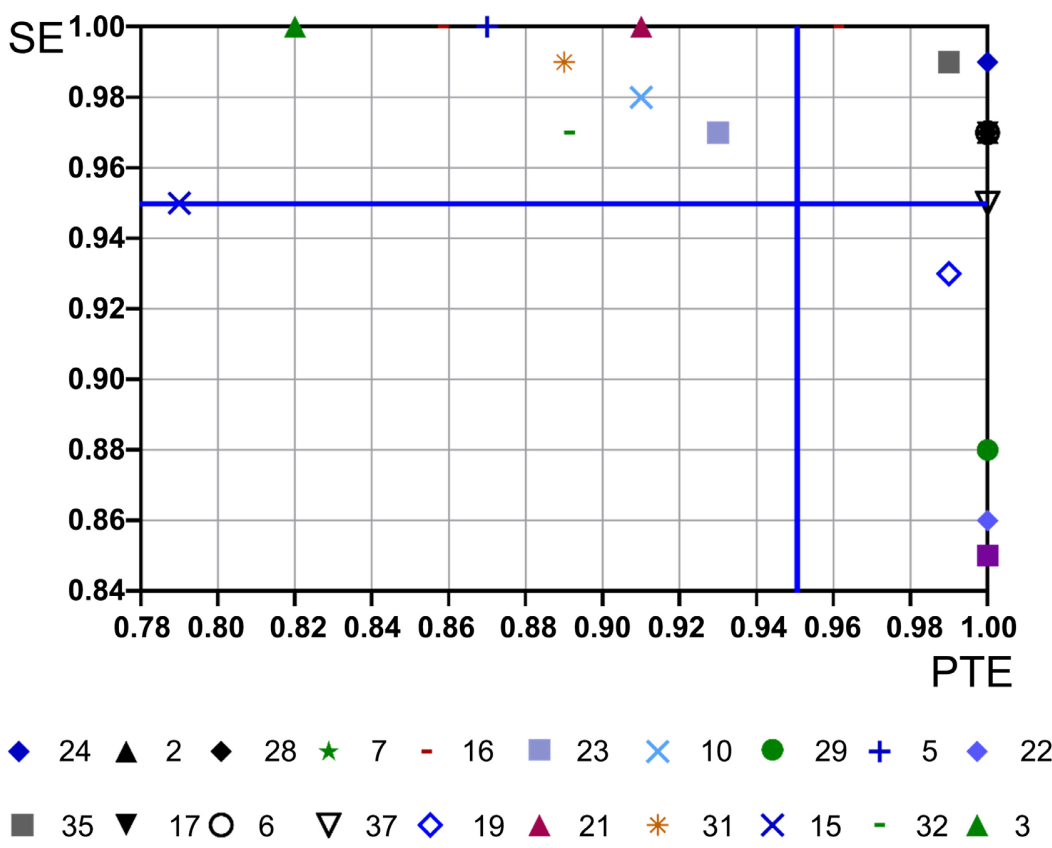

Figure 4. Efficiency spectrum of online lending platform.

effective platforms are no longer listed separately in the pedigree. According to the pure technical efficiency and scale efficiency in Table 3. The quadrant can be divided into four zones with 0.95 as the dividing point. Therefore, the risk control ability of online lending platform can be divided into four types. As shown in Figure 4. The eight network lending platforms with P2P lending platform codes of 2, 6, 7, 16, 17, 24, 28 and 35 are in the "double high" type of high pure technical efficiency and high scale efficiency. Five platforms belong to the "hightech and low scale type", and the P2P loan platform codes are 11, 19, 22, 29 and 37 respectively. These five online lending platforms should pay attention to further improve the optimal allocation of resources to improve scale efficiency. The 
nine online lending platforms with P2P lending platform codes of 3, 5, 9, 10, 15, 21, 23, 31 and 32 belong to "high scale and low technology type".

\section{Conclusion and Policy Recommendations}

This study provides a theoretical explanation of the models involved in the empirical study in accordance with the logical sequence of writing. First of all, in the selection of indicators, not only the meaning of credit risk represented by the indicators is considered, but also the credit risk analysis indicators are finally selected based on the availability of data, and the indicators are handled differently from the previous literature in order to reduce the indicator distortion caused by time period or accidental reasons. In order to deeply analyze the credit risk of P2P network lending financial enterprises, this study designs the DEA model to evaluate the relative credit risk of the enterprise. In the combination of methods, a different research method is adopted from the predecessors, which explains the feasibility of the two used to assess corporate credit risk, and proposes a new idea for subsequent empirical research.

The difference in efficiency between online lending platforms is mainly due to the difference in risk control and management level of online lending platforms. If the size of the enterprise remains unchanged, it is very important to strengthen the level and quantification of risk management to improve its comprehensive efficiency. The risk management level of the platform can be improved in terms of improving liquidity, anti-risk ability and platform openness. For platforms which are not of the "double high" type, it is necessary to improve the technical strength of the platform and the business level. Firstly, the platform should strengthen the pre-borrowing review and refine the review of borrowing information. Secondly, the platform should conduct professional training for employees to improve their awareness of risk control. Finally, the platform should pay more attention to post-loan supervision. It is necessary to understand the use of borrowers' funds to minimize the risk of default. In addition, efficiency indicators do not adequately represent platform risk. It cannot be used as a single evaluation of platform risk. Investors need to fully consider risks and make prudent decisions. P2P network lending platform not only provides a reliable investment channel for social idle funds, but also provides a stable source of funds for borrowers. This alleviates the imbalance between supply and demand of social funds, and meets the needs of the groups that traditional financial institutions can not cover. In China, regulatory authorities and the platform itself should take some measures to control the credit risk of the P2P Internet lending industry. The specific recommendations were as follows:

1) With more specific and pragmatic laws and regulations system, we will promote the standardized construction of online lending platform and realize the sound development of the industry. In the actual implementation process, the regulatory authorities must adhere to the principle of strict law enforcement and investigation when there are laws to abide by. We will severely punish and 
clear illegal platforms, and actively promote the implementation of policies. We should improve the market exit mechanism, which can effectively protect the interests of investors.

2) Government should accelerate the docking of the central bank's credit information system and P2P network lending platform and coordinate the cooperation of multiple departments to establish a full coverage, high standard and deep-seated social credit system, comprehensively recording and rating citizens' credit information and realizing information sharing.

3) For P2P platform, it should actively respond to national policy planning to bear social responsibility and actively innovate and strive for development. P2P platform should also fully play to its role as an information intermediary to improve public awareness of online lending industry and actively carry out risk education for investors.

\section{Limitations and Future Research}

Limitations: In the selection of indicators, in order to make the data objective, fair, accessible and operable, this study only selects some risk indicator data of P2P online loan platform for empirical analysis. Other environmental factors or other financial data that have an impact on the platform's credit status are not considered. If we consider all kinds of data, the empirical model may have better results.

Future research: In the credit evaluation of P2P network lending industry, we can use a reasonable method to bring some environmental factors, macroeconomic factors and other data into the model, making the index data more comprehensive. A new model to study the credit risk management of P2P network lending industry and platform, which makes a more detailed analysis of the credit risk factors of P2P network lending industry and platform.

\section{Conflicts of Interest}

The authors declare no conflicts of interest regarding the publication of this paper.

\section{References}

Ahelegbey, D. F., Giudici, P., \& Hadji-Misheva, B. (2019). Latent Factor Models for Credit Scoring in P2p Systems. Physica A: Statistical Mechanics and Its Applications, 522, 112-121. https://doi.org/10.1016/j.physa.2019.01.130

Altman, E. I. (1968). Financial Ratios, Discriminant Analysis and the Prediction of Corporate Bankruptcy. The Journal of Finance, 23, 589-609. https://doi.org/10.1111/j.1540-6261.1968.tb00843.x

Altman, E. I. (2018a). Applications of Distress Prediction Models: What Have We Learned after 50 Years from the Z-Score Models? International Journal of Financial Studies, 6, Article No. 70. https://doi.org/10.3390/ijfs6030070

Altman, E. I. (2018b). A Fifty-Year Retrospective on Credit Risk Models, the Altman Z-Score Family of Models and Their Applications to Financial Markets and Managerial 
Strategies. Journal of Credit Risk, 14, 1-34.

Bruton, G. D., \& Rubanik, Y. (2002). Resources of the Firm, Russian High-Technology Startups, and Firm Growth. Journal of Business Venturing, 17, 553-576. https://doi.org/10.1016/S0883-9026(01)00079-9

Bülbül, D., Hakenes, H., \& Lambert, C. (2019). What Influences Banks' Choice of Credit Risk Management Practices? Theory and Evidence. Journal of Financial Stability, 40, 1-14. https://doi.org/10.1016/j.jfs.2018.11.002

Casin, P. (2018). Categorical Multiblock Linear Discriminant Analysis. Journal of Applied Statistics, 45, 1396-1409. https://doi.org/10.1080/02664763.2017.1371678

Charnes, A., Cooper, W., Lewin, A. Y., \& Seiford, L. M. (1997). Data Envelopment Analysis Theory, Methodology and Applications. Journal of the Operational Research Society, 48, 332-333. https://doi.org/10.1057/palgrave.jors.2600342

Chen, W., Gai, Y., \& Gupta, P. (2018). Efficiency Evaluation of Fuzzy Portfolio in Different Risk Measures Via DEA. Annals of Operations Research, 269, 103-127. https://doi.org/10.1007/s10479-017-2411-9

Cheng, C. J., \& Zou, H. B. (2009). Toward the Application of CPV Model in the Calculation of Loan Default Probability. Modern Economic Science, 31, 15-20+124.

Cortes, C., \& Vapnik, V. (1995). Support-Vector Networks. Machine Learning, 20, 273-297. https://doi.org/10.1007/BF00994018

Crouhy, M., Galai, D., \& Mark, R. (2000). A Comparative Analysis of Current Credit Risk Models. Journal of Banking \& Finance, 24, 59-117. https://doi.org/10.1016/S0378-4266(99)00053-9

Derbali, A. (2018). How the Default Probability Is Defined by the CreditRisk+ Model? https://hal.archives-ouvertes.fr/hal-01696011/document

Du, G., Liu, Z., \& Lu, H. (2021). Application of Innovative Risk Early Warning Mode under Big Data Technology in Internet Credit Financial Risk Assessment. Journal of Computational and Applied Mathematics, 386, Article ID: 113260. https://doi.org/10.1016/j.cam.2020.113260

Fang, X., Wang, B., Liu, L., \& Song, Y. (2018). Heterogeneous Traders, the Leverage Effect and Volatility of the Chinese P2P Market. Journal of Management Science and Engineering, 3, 39-57. https://doi.org/10.3724/SP.J.1383.301003

Franata, R., Faturohman, T., \& Rahadi, R. A. (2018). The Implementation of Credit Risk Scorecard Model to Improve the Assessment of Creditworthiness in a Peer-to-Peer Lending Company. International Journal of Accounting, 3, 94-105.

Gao, M., Yen, J., \& Liu, M. (2021). Determinants of Defaults on P2p Lending Platforms in China. International Review of Economics \& Finance, 72, 334-348. https://doi.org/10.1016/j.iref.2020.11.012

Gao, Y., Yu, S. H., \& Shiue, Y. C. (2018). The Performance of the P2p Finance Industry in China. Electronic Commerce Research and Applications, 30, 138-148.

https://doi.org/10.1016/j.elerap.2018.06.002

Guo, Y. (2020). Credit Risk Assessment of P2P Lending Platform towards Big Data Based on BP Neural Network. Journal of Visual Communication and Image Representation, 71, Article ID: 102730. https://doi.org/10.1016/j.jvcir.2019.102730

Hamerle, A., \& Rösch, D. (2006). Parameterizing Credit Risk Models. Journal of Credit Risk, 2, 1-36. https://doi.org/10.21314/JCR.2006.045

Honjo, Y. (2000). Business Failure of New Firms: An Empirical Analysis Using a Multiplicative Hazards Model. International Journal of Industrial Organization, 18, 557-574. https://doi.org/10.1016/S0167-7187(98)00035-6 
Horváthová, J., \& Mokrišová, M. (2018). Risk of Bankruptcy, Its Determinants and Models. Risks, 6, Article No. 117. https://doi.org/10.3390/risks6040117

Kabir, M. N., Worthington, A., \& Gupta, R. (2015). Comparative Credit Risk in Islamic and Conventional Bank. Pacific-Basin Finance Journal, 34, 327-353. https://doi.org/10.1016/j.pacfin.2015.06.001

Kale, S., \& Arditi, D. (1998). Business Failures: Liabilities of Newness, Adolescence, and Smallness. Journal of Construction Engineering and Management, 124, 458-464. https://doi.org/10.1061/(ASCE)0733-9364(1998)124:6(458)

Kwok, Y. K. (2020). Efficient Risk Measures Calculations for Generalized CreditRisk+ Models. Social Science Research Network, 20, 1-35. https://doi.org/10.2139/ssrn.3680659

Liu, X. (2020). A Visualization Analysis on Researches of Internet Finance Credit Risk in Coastal Area. Journal of Coastal Research, 103, 85-89. https://doi.org/10.2112/SI103-018.1

Ma, L., Li, Y., Li, D., Li, H., Wang, Y., \& Ren, C. (2020). Risk Identification and Decision Making for P2P Companies: An Empirical Study in the Bohai Coast Regions. Journal of Coastal Research, 106, 191-196. https://doi.org/10.2112/SI106-045.1

Mardhotillah, I. C. (2019). 5c Factor Analysis Aspects of the Designation of Lending of Working Capital in Pd. Bpr Bank Regional Lamongan. Jurnal Studi Manajemen dan Bisnis, 6, 1-7. https://doi.org/10.21107/jsmb.v6i1.6672

Mendelová, V., \& Tatiana, B. (2017). Diagnostikovanie finančného zdravia podnikov pomocou metódy DEA: aplikácia na podniky v Slovenskej republike. Politická ekonomie, 65, 26-44. https://doi.org/10.18267/j.polek.1125

Michalkova, L., \& Michalikova, K. F. (2017). Credit Risk Measurement. New Trends and Issues Proceedings on Humanities and Social Sciences, 3, 168-174. https://doi.org/10.18844/gjhss.v3i4.1562

Morgan, J. P. (1997). Creditmetrics-Technical Document. JP Morgan, New York.

Panigrahi, C. (2019). Validity of Altman's “Z” Score Model in Predicting Financial Distress of Pharmaceutical Companies. Economics and Public Policy, 4, 65-73.

Pérez-Martín, A., Pérez-Torregrosa, A., \& Vaca, M. (2018). Big Data Techniques to Measure Credit Banking Risk in Home Equity Loans. Journal of Business Research, 89, 448-454. https://doi.org/10.1016/j.jbusres.2018.02.008

Razi, M. A., Tarn, J. M., \& Siddiqui, F. A. (2004). Exploring the Failure and Success of DotComs. Information Management \& Computer Security, 12, 228-244. https://doi.org/10.1108/09685220410542598

Sanfins, M. A., Rodrigues ,B. J. P., Santos, D. R., \& Lourenço, R. O. (2020). Credit Risk Calculation: An Application in the Brazilian Market Using the CreditRisk+ Model with Uncertainties. International Business Research, 13, 40-63.

Shen, F., Zhao, X., Li, Z., Li, K., \& Meng, Z. (2019). A Novel Ensemble Classification Model Based on Neural Networks and a Classifier Optimisation Technique for Imbalanced Credit Risk Evaluation. Physica A: Statistical Mechanics and Its Applications, 526, Article ID: 121073. https://doi.org/10.1016/j.physa.2019.121073

Siekelova, A., Kovalova, E., \& Ciurlău, C. (2019). Prediction Financial Stability of Romanian Production Companies through Altman Z-Score. Ekonomicko-Manazerske Spektrum, 13, 89-97. https://doi.org/10.26552/ems.2019.2.89-97

Song, P., Chen, Y., Zhou, Z., \& Wu, H. (2018). Performance Analysis of Peer-to-Peer Online Lending Platforms in China. Sustainability, 10, Article No. 2987.

https://doi.org/10.3390/su10092987 
Stokes, D., \& Blackburn, R. (2002). Learning the Hard Way: The Lessons of Owner-Managers Who Have Closed Their Businesses. Journal of Small Business and Enterprise Development, 9, 17-27. https://doi.org/10.1108/14626000210419455

Tian, Y. (2018). Copulas and Credit Risk Models. European Financial Systems 2018: Proceedings of the 15th International Scientific Conference on European Financial Systems 2018 (pp. 780-787). Czech Republic.

Tung, D. T., \& Phung, V. T. H. (2019). An Application of Altman Z-Score Model to Analyze the Bankruptcy Risk: Cases of Multidisciplinary Enterprises in Vietnam. Investment Management \& Financial Innovations, 16, 181-185. https://doi.org/10.21511/imfi.16(4).2019.16

Wahyuni, N. (2017). Penerapan Prinsip 5C Dalam Pemberian Kredit Sebagai Perlindungan Bank. Lex Journal: Kajian Hukum \& Keadilan, 1, 1-20. https://doi.org/10.25139/lex.v1i1.236

Wang, T., \& Li, J. (2019). An Improved Support Vector Machine and Its Application in P2P Lending Personal Credit Scoring. Materials Science and Engineering, 490, Article ID: 062041. https://doi.org/10.1088/1757-899X/490/6/062041

Wang, H., Fan, K., Li, H., \& Yang, Y. (2020a). A Dynamic and Verifiable Multi-Keyword Ranked Search Scheme in the P2P Networking Environment. Peer-to-Peer Networking and Applications, 13, 2342-2355. https://doi.org/10.1007/s12083-020-00912-7

Wang, Q., Liu, H., He, J., \& Du, X. (2020b). A Graph Attentive Network Model for P2p Lending Fraud Detection. In G. Li, H. Shen, Y. Yuan, X. Wang, H. Liu, \& X. Zhao (Eds.), Knowledge Science, Engineering and Management. KSEM 2020 (pp. 316-327). Springer. https://doi.org/10.1007/978-3-030-55130-8_28

Wang, X., Shi, L., Wang, B., \& Kan, M. (2020c). A Method to Evaluate Credit Risk for Banks under PPP Project Finance. Engineering, Construction and Architectural Management, 27, 483-501. https://doi.org/10.1108/ECAM-06-2018-0247

Wang, L., Wang, Y., Sun, Y., Han, K., \& Chen, Y. (2021). Financial Inclusion and Green Economic Efficiency: Evidence from China. Journal of Environmental Planning and Management, 65, 240-271. https://doi.org/10.1080/09640568.2021.1881459

Yeh, C. C., Lin, F., \& Hsu, C. Y. (2012). A Hybrid KMV Model, Random Forests and Rough Set Theory Approach for Credit Rating. Knowledge-Based Systems, 33, 166-172. https://doi.org/10.1016/j.knosys.2012.04.004

Zeng, Z., Zeng, H., \& Jiang, S. (2021). The Application of KMV Model in China's Insurance Market during the Covid-19. Earth and Environmental Science, 692, Article ID: 032032. https://doi.org/10.1088/1755-1315/692/3/032032

Zhang, W., Zhao, Y., Wang, P., \& Shen, D. (2020). Investor Sentiment and the Return Rate of P2P Lending Platform. Asia-Pacific Financial Markets, 27, 97-113. https://doi.org/10.1007/s10690-019-09284-2

Zhao, C., Li, M., Zhuang, L., \& Wang, J. (2021). Platform Heterogeneity, Competitive Relationship, and Network Lending Efficiency. Emerging Markets Finance and Trade, 57, 2271-2289. https://doi.org/10.1080/1540496X.2019.1694890

Zhou, H., Sun, G., Fu, S., Liu, J., Zhou, X., \& Zhou, J. (2019). A Big Data Mining Approach of PSO-Based BP Neural Network for Financial Risk Management with IoT. Institute of Electrical and Electronics Engineers, 7, 54035-154043.

https://doi.org/10.1109/ACCESS.2019.2948949 